\title{
LA RATIO DECIDENDI EN EL DERECHO COLOMBIANO
}

\section{THE RATIO DECIDENDI IN THE COLOMBIAN LAW}

\begin{abstract}
JHOMNY URREA Abogado Universidad Nacional de Colombia. Especialista en Instituciones Jurídico Penales Universidad Nacional de Colombia. Docente de la asignatura Escuelas de Interpretación Jurídica de la Universidad Santo Tomas sede Villavicencio.
\end{abstract}

Fecha de recepción: 26 de marzo de 2010. Fecha de aprobación: 18 de abril de 2010.

\section{Resumen:}

¿Cómo se puede construir la ratio decidendi de una sentencia judicial? El escrito propone una metodología de lectura de sentencias individuales en Colombia a partir de la discusión de las tesis del profesor Diego López Medina sobre el origen y función de la ratio decidendi. Se describe, en primer lugar, las tesis tradicional y constructivista de la ratio señaladas por López. Después de que es objetada la base de esta distinción -la distinción entre hechos y derechos- se examina, en segundo lugar, tres definiciones de ratio decidendi. Ante sus consecuencias indeseables se propone, finalmente, un concepto de ratio decidendi desarrollado para los tipos de sentencias producidas por la Corte Constitucional. 


\section{REVISTA VIRTUAL VIA INVENIENDI ET IUDICANDI}

"CAMINO DEL HALLAZGO Y DEL JUICIO"

http://viei.usta.edu.co/E-MAIL: revistainveniendi@usantotomas.edu.co

\section{Abstrac:}

How decidendi of a judicial sentence can be constructed to the ratio The writing proposes a methodology of reading of individual sentences in Colombia from the discussion of theses of professor Diego Lopez Medina on the origin and function of the ratio decidendi. It is described, in the first place, the traditional and constructivista theses of the ratio indicated by Lopez. After the base of this distinction is objected - the distinction between facts and rights is examined, secondly, three definitions of ratio decidendi. Before his undesirable consequences one sets out, finally, a ratio concept decidendi developed for the types of sentences produced by the Constitutional Court

\section{Palabras clave:}

Jurisprudencia, ratio decidendi, obiter dictum, precedente.

\section{Key words:}

Judicial sentence, ratio decidendi, obiter dictum, precedent

\section{Identificación del Artículo:}

Reflexión académica. 


\section{REVISTA VIRTUAL VIA INVENIENDI ET IUDICANDI}

"CAMINO DEL HALLAZGO Y DEL JUICIO"

http://viei.usta.edu.co/ E-MAIL: revistainveniendi@usantotomas.edu.co

\section{INTRODUCCIÓN}

Este artículo es una recepción positiva y crítica a la metodología del "Derecho de los Jueces" expuesta por Diego López (2002). Se ubica dentro de un capítulo específico de esta teoría y solo así puede ser comprendido: dentro del "análisis estático de la jurisprudencia", es decir, de la forma como puede leerse una sentencia individual y seleccionarse la ratio decidendi que podría ser precedente para un caso futuro. Sigo a López en la tesis sobre el valor obligatorio de los precedentes en Colombia y con la necesidad de proponer un manejo estructurado de la jurisprudencia ${ }^{1}$ pero discrepo de su opinión cuando liga necesariamente el uso de apartes conceptuales de sentencias, mediante extractos o no, a una ratio decidendi formalista que, presuntamente, subvaloraría los hechos de los casos. La ratio decidendi de una sentencia previa puede ser "hallada" porque cada decisión judicial es, y fue, un acto inteligible similar o equivalente al realizado por un juez posterior. La ratio no es un concepto oscuro e incognoscible que los jueces puedan construir arbitrariamente o develar mágicamente. Si decimos con claridad cual es la ratio de una sentencia previa y sometemos los criterios para preferirla a otra opción al debate público, sujetaremos a jueces y litigantes fuertemente al precedente y a metodologías consistentes de lectura de la jurisprudencia, sin que esto signifique, como propone el autor, la imposibilidad del uso de técnicas legítimas de manipulación de precedentes. Estas últimas son ligeramente

\footnotetext{
${ }^{1}$ López Medina, 2002, El derecho de los Jueces, p. 5.
} 


\section{REVISTA VIRTUAL VIA INVENIENDI ET IUDICANDI}

"CAMINO DEL HALLAZGO Y DEL JUICIO"

http://viei.usta.edu.co/ E-MAIL: revistainveniendi@usantotomas.edu.co

justificadas en El derecho de los jueces mediante el recurso retórico de una ratio antiformalista que no ofrece criterios regulares de lectura específicos y controlables. Las finalidades de las acciones, los tipos de procedimientos y las formas de discusión de los hechos y de los argumentos jurídicos mediante los cuales se producen las diversas sentencias de constitucionalidad, revisión de tutela, tutela, casación, habeas corpus, acciones populares, etc. proveen a los jueces de parámetros abiertos, flexibles y públicos para la selección de la ratio decidendi y, del mismo modo, restringen más su campo de discusión que categorías menos fiables, más generales e intuitivas como los "hechos" y "derechos" de un caso.

El conocido concepto de la ratio decidendi como aquella "formulación general, más allá de las particularidades irrelevantes del caso, del principio, regla o razón general que constituye la base de la decisión judicial especifica" ${ }^{2}$ no aporta soluciones a los problemas prácticos que concita la lectura de la jurisprudencia. Es una definición circular ${ }^{3}$ que puede volverse fructífera si delimitamos los extremos de relevancia para cada tipo de decisión judicial en los cuales se puede ubicar y discutir la ratio decidendi. Abandonar esta labor lectora instintiva y ajena al imperativo de universalidad, igualdad y racionalidad del precedente es mi objetivo.

\footnotetext{
${ }^{2}$ Sentencia SU-047-99, p. 53.

${ }^{3}$ López Medina, 2002, Op. Cit., p. 112.
} 


\section{REVISTA VIRTUAL VIA INVENIENDI ET IUDICANDI}

"CAMINO DEL HALLAZGO Y DEL JUICIO"

http://viei.usta.edu.co/ E-MAIL: revistainveniendi@usantotomas.edu.co

El derecho de los jueces describe y contrapone dos tipos de concepciones sobre la ratio decidendi: una "formal y una "constructivista"4. Para la primera "la ratio parece encontrarse en enunciados y argumentos que expresamente hace el juez anterior $^{, 5} \mathrm{y}$, por tanto, puede ser encontrada en una sentencia previa. Para la segunda, por el contrario, la ratio no esta explícitamente formulada y depende de una "racionalización ulterior de la sentencia por parte del juez que decide el caso nuevo". La diferencia entre ambas posiciones, por lo menos en la visión de López, estriba en el valor asignado a los hechos del caso y su relación con la decisión. Desde lo formal solo son importantes las consideraciones generales doctrinarias que puedan ser extraídas literalmente del texto de la sentencia. Desde lo constructivo, por el contrario, la relación entre hechos y decisión es determinante: ningún argumento genérico de la motivación puede ser entendido sin el contexto fáctico que lo rodea.

Estas dos concepciones son colocadas frente a frente. La visión formal depende de la lectura tradicional, general e impersonal de la jurisprudencia. Esta última se asimila a la ley y los intérpretes se convierten en cazadores de extractos ${ }^{7}$. La forma tradicional se caracteriza porque es "intuitiva" ${ }^{8}$, además, por desconocer la

\footnotetext{
${ }^{4}$ El término es usado por Gordillo y López en Consideraciones ulteriores sobre el análisis estático de jurisprudencia (2002).

${ }^{5}$ López Medina, Op. Cit., p. 116.

${ }^{6}$ Ibídem, p. 108

7 Ibídem, p. 61. Esta “orientación conceptualista” de la jurisprudencia, afirma López, es a la que obedece la sistematización de extractos realizada por la Relatoría de la Corte Constitucional.

${ }^{8}$ Ibídem, p. 117, píe de pagina 121.
} 


\section{REVISTA VIRTUAL VIA INVENIENDI ET IUDICANDI}

"CAMINO DEL HALLAZGO Y DEL JUICIO"

http://viei.usta.edu.co/ E-MAIL: revistainveniendi@usantotomas.edu.co

"densidad argumentativa" del derecho jurisprudencial. La consecuencia de tal método es el oportunismo jurisprudencial: cualquier argumento de la motivación de una sentencia puede ser tomado por ratio decidendi ${ }^{10}$.

Una ratio constructivista, al otro costado, corresponde a la lectura desde el derecho de los jueces. Es la técnica que exige el conocimiento de los casos y no solamente de discursos retóricos sobre el derecho. Las sentencias que deben ser citadas como precedentes deben acercarse a los hechos y no contener un sentido meramente retórico ${ }^{11}$.

\section{II}

El enfrentamiento de ambas posturas que ha realizado López no tiene el alcance tan extenso, opuesto, contradictorio y agudo señalado. La selección de párrafos y proposiciones jurídicas aisladas es ciertamente criticable porque descontextualiza los argumentos fácticos de una decisión previa. Hacer al lado los hechos para centrarse en un discurso jurídico denodadamente abstracto es en verdad un acto miope que desconoce y reduce la amplitud del derecho jurisprudencial. Sin embargo, la ratio constructivista, así presentada, asume erróneamente que los

\footnotetext{
${ }^{9}$ Ibídem, p. 104. Este argumento no se coloca en duda. Se reprocha, como se verá más adelante, solo su uso ilegitimo para justificar una sujeción débil a los precedentes.

10 Ibídem, p.85, 94. También en Gordillo y López (2002): "En el caso de los jueces [se refiere a la dificultades para una citación jurisprudencial idónea], una formación deficiente en las técnicas de interpretación los conduce a que sus citas obedezcan a la intuición, el capricho, el olfato o la mera conveniencia. (...)”. (p. 43). En referencia al derecho alegado por los litigantes: (45) ... [En] el derecho de los litigantes (...) [m] ucho menos deben ser los memoriales depósitos de afirmaciones jurisprudenciales estratégicas que no son, en realidad, la ratio decidendi de la sentencia invocada".

${ }^{11}$ Gordillo y López (2002).Op. Cit., p. 25
} 


\section{REVISTA VIRTUAL VIA INVENIENDI ET IUDICANDI}

"CAMINO DEL HALLAZGO Y DEL JUICIO"

http://viei.usta.edu.co/ E-MAIL: revistainveniendi@usantotomas.edu.co

"hechos" son realidades por sí mismas diferenciables de los argumentos "jurídicos" y que no son percibidos, como realmente sucede, a través de las mismas sentencias. Los hechos se distinguen tanto como los derechos dentro de un mar fragmentos literales. Los extractos de jurisprudencia caóticos no son pues patrimonio exclusivo de los derechos. El uso de extractos para justificar o resaltar determinados hechos de las sentencias no es ajeno a la tesis constructivista y, por tanto, no debería amplificarse como el mayor defecto de la tesis formal. Cuando un juez afirma que la decisión anterior no contenía su verdadero principio o que el caso era distinto al actual debe justificarse no solo en mejores razones, que siempre están a la mano ${ }^{12}$, sino en el manejo explicito y literal de la decisión previa. Dar el paso descrito le exigirá una tarea de selección de argumentos jurídicos o fácticos dispersos a los cuales podrá asignar un mayor o menor peso. ¿Cómo se incorporará este material jurisprudencial literal al nuevo caso? Cada juez imprime su estilo particular y sobre esta base relacionará las decisiones previas de sus colegas. No todos los jueces empezarán o terminaran por el mismo tema ni todas las sentencias serán iguales pero el derecho jurisprudencial, a pesar de la diversidad de discursos, no puede ignorar ni hacer a un lado la referencia explicita de como son y deben ser seleccionados los hechos y

\footnotetext{
${ }^{12}$ Ibidem, p.15. En la presentación de la ratio constructivista por López se da por sentado que el juez posterior busca "el principio que cuadra con los precedentes ya decididos y que ofrece la mejor explicación política y moral de los mismos". Esta suposición no es más que un sofisma: presenta la jurisprudencia como una novela dirigida siempre al progreso y no como una lucha constante por la interpretación. La jurisprudencia, dentro de ciertos límites (ajenos al objeto de este ensayo y definidos por ella misma), es flexible y cambiante. Una doctrina fuerte del precedente solo exige que los cambios y distinciones de los casos sean más exigentes y controlados pero no pide la inmovilidad. La carga del precedente se cumple con jueces que motivan exigentemente sus decisiones y no con jueces que fallan siempre en idéntico sentido.
} 


\section{REVISTA VIRTUAL VIA INVENIENDI ET IUDICANDI}

"CAMINO DEL HALLAZGO Y DEL JUICIO"

http://viei.usta.edu.co/E-MAIL: revistainveniendi@usantotomas.edu.co

derechos con el argumento de que eso es formalismo jurídico. Esta claro que los jueces no solo pueden sino deben citar los precedentes que manejan para justificar cualquier decisión. Ellos tienen una carga de transparencia ${ }^{13}$.

La ratio decidendi constructivista no puede describirse correctamente como aquella que esta al lado de los hechos y la formal de los derechos. Esta impresión que quiere causar López al lector, además de errónea, es usada para ubicar a la teoría del precedente en un ambiente político favorable de recepción. Estar al lado de los hechos, en efecto, puede significar para los derechos fundamentales desarrollos concretos lejanos de las meras promesas. Los abogados "no tradicionalistas" se ubicarían indudablemente con los hechos, un plus técnico, y estarían con los derechos fundamentales -plus moral-. Los abogados "tradicionalistas" quedarían clasificados así estratégicamente como hombres de derechos -menor valor técnico- y, al mismo tiempo, como partidarios de un discurso político sin valor práctico -menos valor moral-.

\section{III.}

Con todo, el mayor inconveniente de la tesis formal no reside en el sobrevalorado énfasis de la descontextualización fáctica sino, como lo destaca el mismo López ${ }^{14}$,

\footnotetext{
${ }^{13}$ Sentencia C-836-01, p.44. Hago referencia a la expresión usada por los Magistrados Manuel Cepeda y Marco Gerardo Monroy Cabra en su aclaración de voto conjunta.

${ }^{14}$ Gordillo y López, 2002, Op. Cit. p. 43, 45.
} 


\section{REVISTA VIRTUAL VIA INVENIENDI ET IUDICANDI}

"CAMINO DEL HALLAZGO Y DEL JUICIO"

http://viei.usta.edu.co/ E-MAIL: revistainveniendi@usantotomas.edu.co

en la selección arbitraria de la ratio decidendi a partir de párrafos y extractos. Por razones desconocidas cualquier argumento aquí y allí puede estar "por encima de las particularidades irrelevantes de un caso" sin que exista un debate público más o menos uniforme entre los jueces - y abogados- sobre cual debería ser la ratio decidendi de una sentencia.

La tesis constructivista debería ofrecernos una solución mejor para la selección de la ratio al ser ubicada con los hechos. La tesis afirma no obstante que son los jueces posteriores quienes deben hallarla o, lo mismo, que no puede ser definida. La ratio decidendi que propone la tesis constructivista da a entender que jamás se puede conocer porque siempre esta en construcción. Esta explicación es francamente extraña, exótica y desconcertante. Las sentencias previas se vuelven incomprensibles $^{15}$ y se espera que los jueces posteriores por medio de una especie de acto mágico resuelvan el asunto.

La inexistencia de debate racional y criterios explícitos de selección de la ratio decidendi de una sentencia previa es precisamente el punto criticable de esta presentación contradictoria de las tesis y trae como consecuencia una sujeción

\footnotetext{
${ }^{15}$ Villamil Portilla, Edgardo (2004), Estructura y redacción de la sentencia judicial. pp. 236-237. “...lo paradojal del asunto reside en que, (...), [se] interpreta ex post, cuales fueron los verdaderos motivos que llevaron a decidir. De conformidad con ello surge una situación absolutamente descaminada, pues emitida una sentencia con alcance de cosa juzgada, leída y analizada en un primer momento por sus autores, inclusive producido el proceso de recepción de ella en la comunidad académica, todavía se ignore cual es la verdadera ratio decidendi que la inspira y por lo mismo se desconozca por algún tiempo cual es el alcance de la cosa juzgada implícita. Según lo que pone de manifiesto esta insólita practica de la jurisprudencia constitucional, no insular sino más bien recurrente, se necesita y es posible, a posteriori dictar una nueva sentencia que fije el alcance de la cosa juzgada de una sentencia pretérita".
} 


\section{REVISTA VIRTUAL VIA INVENIENDI ET IUDICANDI}

"CAMINO DEL HALLAZGO Y DEL JUICIO"

http://viei.usta.edu.co/ E-MAIL: revistainveniendi@usantotomas.edu.co

débil del juez al caso precedente ${ }^{16}$. Tanto la tesis formal como la constructivista se caracterizan por permitir un margen de discrecionalidad no controlable y sumamente arbitrario. Cuando un juez argumenta que no hay ratio decidendi previa, sin que tal criterio de selección pueda ser reproducido por otros jueces para llegar a resultados diversos o similares, puede escoger libremente aquello que le parece mejor: éste hecho, aquel argumento, este párrafo, quizá el otro...

El argumento sobre la inexistencia de la ratio decidendi de una decisión previa es más un recurso retórico ilegitimo para el cambio de precedentes que una definición con sentido. Analicemos el caso mencionado por el autor de los concursos abiertos y cerrados en la Procuraduría y que nos servirá para graficar la crítica: la sentencia C-110-99 es citada como precedente de la C-266-02. Esta situación es analizada detalladamente, cada sentencia que es objeto de análisis es diseccionada realmente, por así decirlo, y la ratio decidendi es expresamente señalada como tal ${ }^{17}$. Veamos: ellos nos dicen que la sentencia C-266-02 abandono el precedente establecido en la C-110-99 ${ }^{18}$. Dicho apartamiento del precedente se habría producido para el autor, y esto es lo que interesa resaltar,

\footnotetext{
${ }^{16}$ Gordillo y López, 2002, Op. Cit., p. 20. Los cambios jurisprudenciales de la Corte Constitucional analizados en esta ficción dual (formal/real) conduce a pensar que aquella tenga la "tendencia de usar la noción de ratio en su sentido formalista o realista, según las necesidades de la argumentación”. En la sentencia C-836 de 2001 (p. 36) se difiere de este enfoque y se afirma, en referencia a la Corte Suprema de Justicia, que la vinculación débil al precedente de las altas cortes se justifica por su posición en la cúspide de la jerarquía judicial y su origen constitucional. La sujeción débil al precedente a que conduce la tesis de López operaría más en el campo de las altas Cortes del Estado pero produciría consecuencias indeseables en los niveles inferiores de la jerarquía judicial formal.

${ }^{17}$ Gordillo y López, 2002, Op. Cit., p. 20.

${ }^{18}$ Ibídem., p. 19.
} 


\section{REVISTA VIRTUAL VIA INVENIENDI ET IUDICANDI}

"CAMINO DEL HALLAZGO Y DEL JUICIO"

http://viei.usta.edu.co/ E-MAIL: revistainveniendi@usantotomas.edu.co

porque la Corte no habría sido formalista ${ }^{19}$. De haberse seguido la tesis formal de la ratio, continúan, el precedente de la C-110-99 se habría aplicado necesariamente ${ }^{20}$. La Corte sigue otro camino y en concepto de los autores " $[\mathrm{e}] \mathrm{s}$ obvio que la desobediencia al precedente se debió a una apropiación y uso antiformalista de la búsqueda de la ratio decidendi”21. La explicación, para abreviar, es que en una sentencia como la C-266-02 "se evidencian al mismo tiempo la presencia de las dos teorías, la formalista y antiformalista, de apreciación de la ratio decidendi"22 . Sin embargo, y que curioso, los mismos autores deben quejarse del argumento "tan rebuscado o litera ${ }^{23 "}$ que usa la Corte para hacer una interpretación que se precia reconstructiva de la ratio. Este caso nos muestra, bajo una presentación menos sensacionalista, que la Corte para distinguir el caso precedente debió resaltar hechos existentes en otras sentencias en desmedro del que, presente en la C-110-99, podría haberle sugerido lo contrario. Este descenso a los detalles, justamente a los hechos que tanta importancia se da, debería ser analizado en lugar de ser descalificado como "rebuscado". El "contexto fáctico" para no seguir un precedente, estas minucias, por consiguiente, son el producto de la selección conciente o instintiva de conjuntos de hechos de sentencias previas. Tal actividad, connatural y legítima de

\footnotetext{
${ }^{19}$ Ibídem, p. 22.

${ }^{20}$ Esta intuición no controlable, este pálpito, nos dice que al menos algún hecho nos sugiere que la C-110-99 debe ser seguida como precedente. ¿Cómo saltamos a decir lo contrario? ¿Cuántos o qué cualificación de los hechos se necesitan para que una decisión anterior sea un precedente y "similar" al caso nuevo?. No lo se pero sería deseable decirlo en las sentencias.

${ }^{21}$ Gordillo y López, 2002, Op. Cit., p. 23.

${ }^{22}$ Ibídem, p. 21.

${ }^{23}$ Ibidem, p. 22. Píe de pagina 37. El argumento es que en la C-110-99 "se contemplaban concursos mixtos" y en la C-266-02 se hablaba sólo de concursos cerrados.
} 


\section{REVISTA VIRTUAL VIA INVENIENDI ET IUDICANDI}

"CAMINO DEL HALLAZGO Y DEL JUICIO"

http://viei.usta.edu.co/ E-MAIL: revistainveniendi@usantotomas.edu.co

la actividad judicial, es la misma que se realiza cuando se escogen argumentos jurídicos y "conceptos" en desmedro de otros y no podría censurarse como "conceptualismo dominante".

\section{IV.}

¿Qué hacer para evitar esta vinculación débil al precedente?. López deja el problema inconcluso en el Derecho de los Jueces pero reflexiona sobre una idea en particular. En el libro, y luego de reafirmar nuevamente la indispensable "conexión entre hechos y resultados vinculantes"24 de la tesis constructivista, reduce el campo de apreciación judicial de la ratio proponiendo, entre otros métodos ${ }^{25}$, una "presunción en contra de la distinción entre obiter y dictum y en contra de la distinción de casos"26. La presunción de que un caso no puede ser distinguido sería una solución al embrollo pues significaría que la sentencia previa, por evolutiva que sea la ratio, tendría un núcleo de sentido mínimo cognoscible e inteligible, que vincularía al juez fuertemente al precedente. El autor no desarrolla la presunción que propone y se refiere a ella indudablemente en un sentido no

\footnotetext{
${ }^{24}$ López Medina, 2002, Op. Cit., p. 125.

${ }^{25}$ Ibídem. P. 125

${ }^{26}$ Ibídem p. 125. La diferencia es entre ratio decidendi y obiter dicta y no entre obiter y dicta. En la página 107 aparte 3.3.1 la expresión "dicta" es usada como igual a "obiter dicta". Así se infiere del titulo y del decurso de la argumentación: "dos clases de dicta en la jurisprudencia constitucional colombiana". En la página 112 se compara explícitamente a la "ratio" y el "dicta" para decir que ambos son conceptos circulares. Dicta significaba en esta página otra vez lo mismo: obiter dicta. Luego, si obiter=obiter dicta y dicta=obiter dicta, la frase no podría decir que hay una presunción entre la distinción entre obiter dicta y obiter dicta sino, y esto es lo que busca evitar la distinción de casos, entre ratio y obiter.
} 


\section{REVISTA VIRTUAL VIA INVENIENDI ET IUDICANDI}

"CAMINO DEL HALLAZGO Y DEL JUICIO"

http://viei.usta.edu.co/ E-MAIL: revistainveniendi@usantotomas.edu.co

legalista $^{27}$. A falta de mejor explicación, porque el libro no nos da luces, podríamos decir que sería una especie de código interpretativo implícito que se esperaría de los jueces para que evitaran saltarse frecuentemente los precedentes. Pero un código por el solo hecho de ser implícito, y esta es la consecuencia, no garantizaría una sujeción fuerte al precedente. Una presunción corresponde al modo de obrar por instinto del que se acusa a la tesis formal y su campo de aplicación se volvería ineficaz porque todo caso podría ser distinguido y justificado con base en una ratio antitradicional. La regla general no tardaría en convertirse en la excepción.

V.

Un criterio muy parecido al anterior presume que un grupo de argumentos explícitamente señalado y declarado como ratio decidendi por un juez previo debe ser respetado y no puede variarse salvo que se intente un cambio explicito de jurisprudencia. La "cláusula Angarita" usada en un tiempo por la Corte Constitucional nos recuerda esta actitud voluntarista de la ratio ${ }^{28}$. La cláusula suscita fuertes resistencias al precedente -un juez que se aparta de un fragmento

\footnotetext{
${ }^{27}$ En sentido legalista sería tano como hablar de "jurisprudencia vigente" o "jurisprudencia derogada". Estos conceptos son erróneos. De las leyes se puede hablar con toda propiedad de la vigencia. De la jurisprudencia, a lo sumo, de su valor como precedente para el caso posterior. El autor aclara suficientemente la diferencia entre un derecho de origen legal y uno jurisprudencial como para que pudiera entenderse que la presunción se establecería mediante una reforma legal.

${ }^{28}$ Sentencia C-836-01. En esta sentencia se hace uso de la cláusula Angarita. La decisión se modula incorporando a la ratio decidendi un extenso fragmento de la parte motiva. La C-836-01, fundamental para el impulso del precedente, ofrece la misma resistencia a la cláusula Angarita porque la Corte intenta imponerlo paradójicamente mediante una ratio voluntarista. Se critica este tipo de ratio para eliminar esta resistencia.
} 


\section{REVISTA VIRTUAL VIA INVENIENDI ET IUDICANDI}

"CAMINO DEL HALLAZGO Y DEL JUICIO"

http://viei.usta.edu.co/ E-MAIL: revistainveniendi@usantotomas.edu.co

de sentencia expresamente señalado como ratio decidendi podría ser percibido como alguien que no respeta la cosa juzgada- pero pretende vincular fuertemente a los jueces a diferencia de la tesis de Diego López -uno se puede desvincular fácilmente de un fragmento obligatorio diciendo que la ratio evoluciona-. Una razón ya analizada explicaría esta resistencia: los jueces cuando analizan precedentes seleccionan hechos y derechos dentro de un amplio campo de discrecionalidad. El juez posterior con justa razón se siente molestamente atado a la voluntad de su predecesor y se siente coaccionado pues no puede ejercer las facultades de pesar y valorar que le son inherentes. La cláusula también presenta el inconveniente de que una ratio declarada es solo un criterio entre muchos posibles que puede ser evaluado y desafortunadamente el más inseguro. La voluntad del juez puede dictaminar que la ratio sea cualquier cosa y tampoco existiría un control racional de las preferencias. La exegesis jurisprudencial propugnada por esta idea depende de la voluntad del juez tanto como la exegesis legal de la voluntad del legislador y no parecería ser la mejor opción. Pero se puede discrepar por razones más importantes: las declaraciones voluntaristas de ratio decidendi de los jueces no son obligatorias si se tiene en cuenta que los procedimientos judiciales filtran los hechos $y$ los derechos que ingresan a las sentencias. Un juez no escoge hechos y derechos porque su predecesor lo imponga sino porque el proceso lo permite. Los hechos de un caso posterior que van a ser comparados con los casos precedentes no pueden ser escogidos simplemente por su "similitud fáctica" o por la fidelidad al juez anterior sino, fundamentalmente, porque tienen sentido dentro 


\section{REVISTA VIRTUAL VIA INVENIENDI ET IUDICANDI}

"CAMINO DEL HALLAZGO Y DEL JUICIO"

http://viei.usta.edu.co/ E-MAIL: revistainveniendi@usantotomas.edu.co

de los tipos de argumentación permitidos en el proceso nuevo. La voluntad de los jueces, entonces, puede coincidir con la ratio construida pero no a la inversa. Un ejemplo aclarará esta explicación. Si un juez de tutela dijera en su sentencia que interpreta el ordenamiento legal de determinada forma y adicionalmente intenta atar a los jueces posteriores declarando que esa es la ratio decidendi, considerado cierto grupo de hechos $\mathrm{A}$, un juez de tutela posterior solo estaría vinculado al caso como precedente, si y solo sí, dicho resultado fuera consecuencia de la interpretación de los derechos fundamentales. Solo los argumentos de la sentencia de tutela previa que interpretasen los derechos fundamentales serían componentes de la ratio decidendi controlante del caso posterior -en tutelaaunque la voluntad del juez previo quisiera dictaminar lo contrario. Luego, las interpretaciones del ordenamiento legal efectuadas en casos de tutela previos no harían parte de la ratio decidendi: el proceso posterior (tutela) y su forma específica de filtrar los derechos (fundamentales: ratio decidendi) impide que las declaraciones voluntaristas de los jueces (la ratio decidendi comprende derechos legales) tuvieran algún valor (son obiter dictum). Una interpretación legal, por el contrario, si podría tener el carácter de ratio decidendi en una sentencia de casación. Otro ejemplo pero esta vez entre sentencias del mismo tipo: un juez $Q$ falla una acción de tutela por vulneración de un derecho fundamental W y declara que esa es la ratio decidendi que deben seguir los jueces posteriores. A pesar de la voluntad del juez y, considerado un grupo de hechos similares $Z$ que llevan a la vulneración de $\mathrm{W}$, no hay ratio decidendi para un caso posterior y se puede tomar 


\section{REVISTA VIRTUAL VIA INVENIENDI ET IUDICANDI}

"CAMINO DEL HALLAZGO Y DEL JUICIO"

http://viei.usta.edu.co/E-MAIL: revistainveniendi@usantotomas.edu.co

una decisión No-K si se considera que, v.g, existen mecanismos de defensa en el proceso actual que no fueron evaluados por Q. En este caso observamos nuevamente el peso del proceso sobre el juez: el filtro que exige la acción de tutela (valoración de mecanismos de defensa: ratio) impide que la declaración voluntarista del juez anterior prime si no fue examinada (obiter dictum). Todo proceso judicial formal exige de las sentencia determinado pronunciamiento puntual que no coincide necesariamente con el pronunciamiento de un juez anterior (v.g. El habeas corpus no esta pensado para resolver asuntos de alimentos. Todo pronunciamiento voluntarista sobre alimentos en un habeas corpus, llevando este ejemplo al extremo, sería un obiter dictum). Estas exigencias del proceso específico constituyen propiamente hablando la ratio decidendi de un caso y por esta razón cada vez que se falla un caso nuevo en un mismo tipo de sentencia siempre se evaluarán lo mismos asuntos a pesar del mundo diverso de los hechos ${ }^{29}$. La ratio no es un concepto útil si al menos no hay un punto de referencia común de discusión entres los jueces. No habrá punto común de encuentro, no habrá un verdadero punto de derecho que sea precedente, si partimos de las afirmaciones que deseen los jueces.

\footnotetext{
${ }^{29}$ Esta afirmación no excluye que las finalidades de las acciones sean redefinidas por los propios jueces quienes enfrentan diariamente el mundo de los hechos. Los conceptos de "derecho fundamental", "mecanismo de defensa judicial" y "perjuicio irremediable", por ejemplo, han sido redefinidos muchas veces por la jurisprudencia de la Corte Constitucional. Estas redefiniciones son una labor elogiable de la jurisprudencia. Lo único que deseo destacar es que estos conceptos a pesar de los cambios siguen siendo puntos de referencia útiles: pueden ayudar a construir la ratio decidendi de un material jurisprudencial existente.
} 


\section{REVISTA VIRTUAL VIA INVENIENDI ET IUDICANDI}

"CAMINO DEL HALLAZGO Y DEL JUICIO"

http://viei.usta.edu.co/ E-MAIL: revistainveniendi@usantotomas.edu.co

La ratio que estoy describiendo es preferible a la formal porque evita el voluntarismo judicial jurisprudencial -no todo lo que digan los jueces en sus sentencias es ratio decidendi-, ataca la ilusión de ausencia interpretativa de los precedentes que causa la cláusula Angarita -los jueces posteriores si interpretan los precedentes a pesar de las restricciones que quisieran imponer sus colegas-, responde a la objeción de la intangibilidad de la cosa juzgada -la cosa juzgada no es lo que quieran los jueces- $y$, aunque no se lo propuso, hace una replica a aquellos que consideran los precedentes como una intromisión de los jueces en el poder legislativo (los jueces siguen precedentes, argumentos para los casos futuros, no siguen ordenes de sus predecesores) ${ }^{30}$.

La definición de la ratio decidendi es el interrogante no resuelto por el Derecho de los Jueces y la cláusula Angarita intenta responderlo oponiéndose al carácter hermenéutico de los precedentes.

\section{VI.}

En Consideraciones ulteriores sobre el análisis estático de jurisprudencia, López trata de atar este cabo suelto mediante la técnica de citación de sentencias.

\footnotetext{
${ }^{30}$ La ratio voluntarista permite a los críticos del precedente ubicar al problema en las fuentes del derecho y traer a colación la discusión repetida sobre el artículo 230 de la Constitución Política. Cómo la ratio voluntarista propone jueces que legislan para sus colegas -en todo el sentido del término- los críticos objetan que la jurisprudencia no es fuente obligatoria de derecho a fin de sustraerse de estas molestas órdenes. Pero si la ratio no procede de la voluntad del juez previo, como estoy sugiriendo, es evidente que la crítica pierde sentido.
} 


\section{REVISTA VIRTUAL VIA INVENIENDI ET IUDICANDI}

"CAMINO DEL HALLAZGO Y DEL JUICIO"

http://viei.usta.edu.co/ E-MAIL: revistainveniendi@usantotomas.edu.co

¿Cuáles sentencias se acercan a los hechos de un caso posterior?. Aquellas, nos dice, que citan "la ratio decidendi o la sub-regla de una sentencia anterior con un vínculo fáctico amplio o estrecho ${ }^{31}$. En otras palabras: las que citan la ratio decidendi. En el segundo orden, se encuentran las "citaciones conceptuales" finalmente, las "caóticas o meramente retóricas" 33 . De esta clasificación deseo destacar la exigencia necesaria pero supervalorada de que la citación correcta para el caso concreto crece con los hechos y decrece con los derechos. La escala propuesta por López ubica a los derechos en el margen inferior de citación - pues de lo conceptual se pasa a lo meramente retórico- y coloca en primer lugar a la citación fáctica. Hemos visto, a pesar de ello, que esta imagen no es cierta. Los hechos también son seleccionados, filtrados escogidos y entre ellos pueden establecerse jerarquías: ninguno tiene ex ante un mayor valor. Un hecho convenientemente valorado puede ser tan estrecho, abierto o incluso meramente retórico como se quiera y podría darnos la impresión, como a los autores en el caso de los concursos de la Procuraduría, de que es bien "rebuscado". Este caso alabado como "antiformalista" fue precisamente, y usando sus propios términos, una citación meramente retórica de los hechos. Los hechos, los argumentos fácticos y conceptuales pueden ser tan estrechos, abiertos o desfasados según el ángulo deseado. Esta indeterminación es normal en el derecho y no debe sorprendernos; por sí sola nos muestra que la "analogía fáctica" no es el criterio

\footnotetext{
${ }^{31}$ Gordillo y López, 2002, Op. Cit., p. 29. En la p.45, recuerdo al lector, se da mayor relevancia a la analogía fáctica "estrecha" que a la "abierta".

${ }_{32}^{32}$ Ibídem p. 32

${ }^{33}$ Ibídem, p. 35.
} 


\section{REVISTA VIRTUAL VIA INVENIENDI ET IUDICANDI}

"CAMINO DEL HALLAZGO Y DEL JUICIO"

http://viei.usta.edu.co/E-MAIL: revistainveniendi@usantotomas.edu.co

pertinente para ubicar un punto de referencia común entre las sentencias de los jueces, es decir, una ratio decidendi.

La línea "fácil" de jurisprudencia sobre ambigüedad genital realizada por López (SU-337-99, T-551-99, T-692-99 y T-1390-00) nos ilustrará esta situación. Aunque todas las sentencias de la línea tienen hechos indudablemente similares -analogía fáctica- existe una sentencia cuya ratio decidendi puede construirse al margen de los hechos: la T-551-99. En esta sentencia a pesar de que los hechos son similares -hay indudablemente una analogía fáctica estrecha- y de que la Corte dice reiterar jurisprudencia sobre ambigüedad genital no se toma la decisión con base en la ambigüedad sino en realidad sobre el hecho de que la cirugía a la menor ya había sido realizada. Un hecho superado motiva la decisión de no tutelar -no hubo nada sobre que fallar- y todo el discurso de la ambigüedad genital en esta sentencia puede ser comprendido perfectamente como obiter dictum. Que un solo caso -límite- muestre el defecto de centrarse en "los hechos" como si fueran superiores no es muy significativo, pero que todo un sistema de jurisprudencia los ignore y hasta pueda basarse en esta ignorancia ya debería ser un indicativo de que la escala propuesta por López es insuficiente para explicar el problema de la ratio. 


\section{REVISTA VIRTUAL VIA INVENIENDI ET IUDICANDI \\ "CAMINO DEL HALLAZGO Y DEL JUICIO" \\ http://viei.usta.edu.co/ E-MAIL: revistainveniendi@usantotomas.edu.co}

Nuestra Corte Constitucional produce sentencias constitucionalidad que ignoran por completo "los hechos"34. La citación prioritaria de sentencias de constitucionalidad en cualquier tipo de sentencias del ordenamiento jurídico -por su mayor peso como precedente: dinámica- en la práctica nos enseña como una citación conceptual puede ser preferible a una "fáctica" inclusive si es "estrecha": toda la escala se pone de cabeza.

La línea de jurisprudencia sobre el valor del precedente que López realiza mezcla indiscriminadamente sentencias de constitucionalidad y revisión de tutela sin aclarar antes -dinámica- como debería hacerse la citación correcta ${ }^{35}$. Mientras las primeras carecen de hechos y son superabundantes en conceptos las segundas estas compuestamente prioritariamente de hechos; pero cualquier elemento fáctico o jurídico comparable "abierta" o "estrechamente" entre una y otra desempeñan, en principio, una función distinta y no podría ser de otra manera pues cada proceso también lo es. La citación técnica propuesta por López solo puede funcionar, y en realidad se limita insuficientemente a eso, cuando se trata de sentencias del mismo tipo. Cuando se trata de sentencias del mismo tipo es muy fácil hablar de "sentencia fundadora", "sentencia hito" y "sentencia confirmadora de principio" porque el contexto de cada argumento no se perdería si

\footnotetext{
${ }^{34}$ López trata de asimilar ciertas características de las sentencias de constitucionalidad a "los hechos" para matizar un poco su distinción entre hechos y derechos que fundamenta su diferencia entre ratio formalista y antiformalista pero implícitamente acepta con ello una visión dura de los hechos. Por visión dura entiendo aquí adjudicar a un objeto una realidad "externa" y separada de las palabras.

${ }^{35}$ López Medina, 2002, Op. Cit. La línea de jurisprudencia que se desarrolla en el capitulo uno del libro parte de comparar, entre otras, a las siguientes sentencias: C-113-93, C-131-93, C-083-95, T-123-95, T-260-95, C037-96. T-009-00, T-068-00.
} 


\section{REVISTA VIRTUAL VIA INVENIENDI ET IUDICANDI}

"CAMINO DEL HALLAZGO Y DEL JUICIO"

http://viei.usta.edu.co/E-MAIL: revistainveniendi@usantotomas.edu.co

lo entendiéramos dentro del proceso al que sirve. Entre sentencias de tipo diferente el peso y jerarquía asignado al precedente, un problema muy polémico por cierto, hace inoperante los conceptos de "fáctico", "estrecho", "abierto", "conceptual" o "meramente retórico". Los conceptos de las sentencias de constitucionalidad o de ilegalidad por inconstitucionalidad del Consejo de Estado parecerían primar sobre cualquier analogía "fáctica" que se intentase en un caso. Esto significa que el análisis dinámico de la jurisprudencia debería desarrollar el problema de la jerarquía, peso y modo de citación entre precedentes de distintas sentencias de un ordenamiento jurídico y la resolución de dicho problema sería primordial e imprescindible para un modelo de citación técnica -de disciplina del precedente-. "El derecho de los jueces" no aborda el problema del valor del precedente entre sentencias de diverso tipo. Este ensayo solo propone criterios para sentencias del mismo tipo y dejará abierto el interrogante para sentencias diversas.

VII.

¿Cómo definir la ratio? El enfoque que se propone aquí es el de una ratio constructivista -los jueces posteriores seleccionan el material que puede ser precedente: hallan el verdadero principio de la decisión- pero compatible con el análisis racional de sentencias anteriores -la ratio puede ser hallada, no es incognoscible y solo determinado material puede ser válido como ratio decidendi-. 


\section{REVISTA VIRTUAL VIA INVENIENDI ET IUDICANDI}

"CAMINO DEL HALLAZGO Y DEL JUICIO"

http://viei.usta.edu.co/ E-MAIL: revistainveniendi@usantotomas.edu.co

No abandono la distinción entre analogía fáctica, conceptual y caótica porque es útil entre sentencias del mismo tipo para la selección del material jurisprudencial. Simplemente afirmo y agrego que los puntos comunes entre sentencias están dados por las configuraciones de las acciones y procesos.

Sacar extractos de jurisprudencia no es equivocado siempre y cuando tal labor este preordenada a dar orden y sentido a un material previo. ¿Cómo identificar en últimas la ratio decidendi? La Constitución y la legislación, los tipos de procedimiento, nos ofrecen criterios públicos flexibles dentro de los cuales pueden ser y de hecho son entendidas ordinariamente las decisiones de los jueces. Cuando decimos que existen diversos tipos de sentencia y procedimiento señalamos en realidad que existen muchos tipos de ratio decidendi y no un concepto unitario. Es muy común hablar de la ratio en singular pero el derecho jurisprudencial enseña otra cosa: los hechos son diversos y la multiplicidad de acciones existentes dentro de los cuales pueden ser enmarcados es igualmente variada. La anatomía de las acciones judiciales debería servimos para seleccionar la ratio decidendi de los casos precedentes y en lugar de ser descripciones formales de los manuales de procedimiento pasarían a dar sentido tanto a los casos concretos como al estudio de la jurisprudencia.

¿Cómo nace cada decisión judicial?. Las normas, en un sistema de derecho escrito, generalmente describen los diversos tipos de decisión judicial. El catalogo 


\section{REVISTA VIRTUAL VIA INVENIENDI ET IUDICANDI}

"CAMINO DEL HALLAZGO Y DEL JUICIO"

http://viei.usta.edu.co/E-MAIL: revistainveniendi@usantotomas.edu.co

es interminable: La acción de constitucionalidad, la acción de tutela, el habeas corpus, la nulidad, la nulidad y restablecimiento del derecho, la acción popular, la acción de grupo, un proceso ordinario de divorcio, una adopción, una causa penal, un auto de un juez de garantías sobre legalidad de captura, etc. La ratio decidendi en cada caso es distinta pues en cada decisión se discuten temas distintos y las prioridades no siempre son las mismas. Es más: los "hechos" no son lo mismo en cada tipo de decisión y hasta usar este término puede volverse problemático. Muchas veces asociamos los hechos a realidades perceptibles por los sentidos pero esto es cierto solo si es en función de determinadas proposiciones normativas ${ }^{36}$. La división entre hechos y derechos que fundamenta la que puede haber entre ratio formalista y antiformalista quiere hacernos ver lo contrario; las sentencias y la misma legislación empero nos ofrecen elementos muy divergentes y hasta contradictorios: la falta de la una tapa de alcantarilla (un hecho que podría denominarse en sentido estricto: puede ser percibido por sentido común), la existencia de un perjuicio irremediable (un concepto jurídico medio no percibible por los sentidos y que depende de su relación con hechos estrictos) o incluso un concepto judicial (por la vía directa en casación se atacan conceptos, palabras, del juez de instancia) puede llegar a ser un hecho en función del tipo proceso en el cual se haya inscrito. Esta diversidad de elementos es la mejor muestra de que el concepto de hechos es muy simplista ${ }^{37}$. La ratio decidendi no

\footnotetext{
${ }^{36}$ Vernengo, R. J. (1977).

${ }^{37}$ El 12 de agosto encontré en la Web una descripción del artículo de Goodhart que aparece citado en la bibliografía del Derecho de los Jueces. No conozco desafortunadamente su articulo (fundamental para el
} 


\section{REVISTA VIRTUAL VIA INVENIENDI ET IUDICANDI \\ "CAMINO DEL HALLAZGO Y DEL JUICIO" \\ http://viei.usta.edu.co/ E-MAIL: revistainveniendi@usantotomas.edu.co}

puede ser únicamente la comparación simple, estrecha o abiertamente "fáctica", entre una masa amorfa de hechos y derechos perfectamente reconocibles.

Analizaré la ratio de las decisiones de las sentencias de constitucionalidad y tutela señalando al tiempo algunos ejemplos. Las escalas para reconocimiento de la ratio que se proponen aquí partirán de casos de alta, media y baja discrecionalidad. Los casos de baja discrecionalidad se caracterizan porque las razones justificatorias excluyen binariamente motivos (si o no: no puede haber puntos intermedios. Son casos fáciles); en el punto medio existe una discusión entre los interpretes que puede ser reconducida a parámetros fijados por los tipos de procedimiento de cada decisión judicial; en último lugar, están los casos de alta discrecionalidad en los cuales la ratio no es reconocible ni reconducible. La definición de la ratio decidendi como la "formulación general, más allá de las particularidades irrelevantes del caso, del principio, regla o razón general que constituye la base de la decisión judicial específica" así formulada solo es operativa en los niveles de alta discrecionalidad que se describirán.

Debe recordarse que la ratio decidendi más que un enunciado lacónico es, como ha explicado el profesor López $z^{38}$ y no debería olvidarse, una justificación global.

\footnotetext{
tema de este artículo) pero fue interesante encontrar (en una fuente secundaria) que el concepto de ratio decidendi que parte de los hechos y la decisión -el mismo concepto propuesto por López- puede parecerle a Goodhart muy simplista por cuanto, como dice el glosador, "La misma serie de hechos puede parecer por completo diferente para dos distintas personas". Batiza Rodolfo, p. 97. La "ratio decidendi" en la jurisprudencia y la doctrina angloamericanas".

${ }^{38}$ López Medina, 2002, Op. Cit., p. 77. La misma advertencia debe recordarse aquí.
} 


\section{REVISTA VIRTUAL VIA INVENIENDI ET IUDICANDI}

"CAMINO DEL HALLAZGO Y DEL JUICIO"

http://viei.usta.edu.co/ E-MAIL: revistainveniendi@usantotomas.edu.co

Una justificación es una explicación, un discurso corto o extenso sobre como debería manejarse un grupo de argumentos diseminados en una y en muchas sentencias. Así, cuando se dice que los "derechos fundamentales" son un componente de la ratio decidendi de una sentencia de tutela esto significa que los argumentos, fácticos y conceptuales que se seleccionen pueden y deben ser redirigidos a este punto. De todas formas tal paso debe ser justificado como parte de la nueva decisión y no solo meramente como un enunciado estéril.

¿Qué es lo "relevante" para fallar cada caso en los diversos tipos de decisión judicial? ¿Cuál es la ratio decidendi?

\section{VIII.}

El decisum de la sentencia de constitucionalidad es la exequibilidad, la inexequibilidad o la inhibición frente a un grupo de proposiciones normativas. La ratio decidendi, se dice, es una relación entre hechos y derechos. El proceso de constitucionalidad nos dice, sin embargo, que hablar de hechos es sumamente problemático. El resultado de la comparación, en virtud de la supremacía de la Constitución y la competencia de la Corte Constitucional, entre las interpretaciones de normas sujetas a control y la interpretación de la Constitución, forma la ratione decidendi de este tipo de sentencias. No hay componentes particulares de la ratio a los que pueda reconducirse la discusión pues la 


\section{REVISTA VIRTUAL VIA INVENIENDI ET IUDICANDI}

"CAMINO DEL HALLAZGO Y DEL JUICIO"

http://viei.usta.edu.co/ E-MAIL: revistainveniendi@usantotomas.edu.co

Constitución misma no restringe los tipos de razones que podrían justificar una sentencia de constitucionalidad. La discrecionalidad es muy alta: es la interpretación total de la Constitución.

Hay casos de discrecionalidad baja o casos limite fácilmente reconocibles. La declaratoria de exequibilidad o de inexequibilidad por vicios de forma es un caso límite de minima discrecionalidad: la ratio decidendi que puede ser seleccionada como controlante del caso nuevo no corresponde a argumentos materiales o de fondo a pesar de que estén diseminados en la sentencia. Las inhibiciones (ausencias de decisión, pero de todos modos son una decisión) también constituyen casos límite: a pesar de los discursos sofisticados que puedan incorporarse a la sentencia, la ratio decidendi se reduce a la causa de inhibición.

Las analogías o disanologías pueden hacerse más estrechas cuando de sentencias de constitucionalidad condicionada, integradora y sustitutiva se trata ${ }^{39}$. En estos eventos existe una interpretación normativa entre varias posibles que se ajusta a la Constitución, una circunstancia omitida que se agrega para que la norma sea constitucional y una regulación constitucional transitoria directa efectuada por el tribunal constitucional. Las razones expresas señaladas exigen una carga alta de argumentación al tribunal a pesar de la alta discrecionalidad de la ratio y restringen las analogías a los casos del decisum. En las sentencias de

\footnotetext{
${ }^{39}$ Olano García, Hernán Alejandro (2004). .
} 


\section{REVISTA VIRTUAL VIA INVENIENDI ET IUDICANDI}

"CAMINO DEL HALLAZGO Y DEL JUICIO"

http://viei.usta.edu.co/ E-MAIL: revistainveniendi@usantotomas.edu.co

constitucionalidad "simple", por el contrario, no existen modulaciones del decisum por lo que las analogías que pueden realizarse son muy abiertas.

La sentencia de constitucionalidad, uno de los modelos orientadores de selección de la ratio e impulsor de la teoría del precedente en Colombia constituye un caso no el único ${ }^{40}$ - irreconocible, supremamente discrecional y amorfo de selección de la ratio ${ }^{41}$

\section{IX.}

El decisum de la acción de tutela es una orden de actuación o abstención a un sujeto, si se decide tutelar, o una negativa de protección estatal. Los hechos son más reconocibles y se refieren a la acción u omisión predicada de la autoridad pública o el particular, a las diversas cualidades que configuran y pueden predicarse de las acciones legales disponibles para un sujeto o a los daños que

\footnotetext{
${ }^{40}$ Los conceptos de la Sala de Consulta y Servicio Civil del Consejo de Estado son otro caso extraño y debería exigir un análisis a la luz de la teoría del precedente (de crítica y revalorización). ¿Qué valor tienen estos conceptos no vinculantes de un Tribunal de la más reconocida importancia en el ordenamiento para los demás?. Un concepto de la Sala de Consulta y Servicio Civil del Consejo de Estado, visto desde la perspectiva del precedente, no es más que un conglomerado de buenas opiniones (ni siquiera cabe en la categoría de obiter dictum porque no hay decisum. Es más: son a petición de una sola parte -Gobierno- y no hay contradicción). Otro caso extraño hoy en día y frecuente es la posición de la Sala Penal de la Corte Suprema de Justicia cuando dice hacer declaraciones pedagógicas en sus sentencias ¿Qué tipo de declaraciones son estas a luz de la teoría del precedente? Gran parte de estas declaraciones pedagógicas coincidirían probablemente con la ratio decidendi de la sentencia respectiva pero seguramente, y tal vez en mayor grado, serían obiter dicta. Los tribunales y jueces deben hacer pedagogía mediante las decisiones que toman. No se hace pedagogía judicial cuando no se ha resuelto un caso.

${ }^{41}$ La razón por la cual el Tribunal Constitucional esta atado débilmente al precedente en materia de constitucionalidad no esta atada simplemente a un criterio de autoridad. El mismo proceso de constitucionalidad -La Constitución frente a todo- impone esta discrecionalidad.
} 


\section{REVISTA VIRTUAL VIA INVENIENDI ET IUDICANDI}

"CAMINO DEL HALLAZGO Y DEL JUICIO"

http://viei.usta.edu.co/E-MAIL: revistainveniendi@usantotomas.edu.co

podrían o no constituir un perjuicio irremediable. A diferencia de la acción de constitucionalidad existe una discrecionalidad media para la selección de la ratio. Las analogías o disanalogías y los conceptos pueden ser seleccionados en una sentencia previa a la luz de tres parámetros. Del artículo 86 de la Constitución Política de 1991 podemos deducirlos:

- Porque el Juez considera que se han violado o no los derechos fundamentales.

- Porque existen o no otros medios de defensa judicial.

- Porque hay o no perjuicio irremediable.

La Constitución mantiene, desde la perspectiva de una decisión favorable, ligados los conceptos así:

- Hay decisión favorable si se violan derechos fundamentales y no existen mecanismos de defensa.

- Hay decisión favorable si hay violación de derechos fundamentales y a pesar de que existen mecanismos de defensa existe la amenaza de un perjuicio irremediable.

Hemos mantenidos separados los tres componentes de la ratio decidendi porque, los jueces muchas veces ${ }^{42}$, sino en el total de los casos, evalúan los tres factores

\footnotetext{
${ }^{42}$ Este análisis realizado sobre una línea de jurisprudencia concreta será objeto de otro ensayo.
} 


\section{REVISTA VIRTUAL VIA INVENIENDI ET IUDICANDI}

"CAMINO DEL HALLAZGO Y DEL JUICIO"

http://viei.usta.edu.co/ E-MAIL: revistainveniendi@usantotomas.edu.co

en múltiples combinaciones. Estas combinaciones pueden usarse al hacer la síntesis jurisprudencial. Lo importante, en todo caso, es dar una idea clara del pensamiento de la sentencia y permitir puntos, nodos de discusión.

En casos de discrecionalidad baja o límite existen muchas variedades. A modo de ejemplo pueden señalarse los siguientes:

a. Porque el tribunal considera que se dictó "resolución, administrativa o judicial, que revoque, detenga o suspenda la actuación impugnada"43.

b. El desistimiento del recurrente admitido ${ }^{44}$.

c. No hay legitimidad en la persona ${ }^{45}$.

d. El hecho está superado ${ }^{46}$.

\footnotetext{
${ }_{43}^{43}$ Decreto 2596 de 1991. Articulo 26.

${ }^{44}$ Ibídem.

${ }^{45}$ En la sentencia T-249 de 1998, por ejemplo, se "reitera" -sentencia confirmadora de principio- que la posesión no es un derecho fundamental amparable por vía de tutela. ¿Es esta la ratio de esta sentencia? No -es irrelevante que confirme un principio y poco vale la analogía fáctica-. La persona afectada con la acción u omisión en el caso concreto había muerto y la persona que presentó la acción de tutela en su favor no acredito un poder anterior para tal fin o de sus herederos. Luego, a pesar de la declaración, la ratio de la decisión es la falta de legitimidad.

${ }^{46}$ Ver los casos de ambigüedad genital ya citados.
} 


\section{REVISTA VIRTUAL VIA INVENIENDI ET IUDICANDI}

"CAMINO DEL HALLAZGO Y DEL JUICIO"

http://viei.usta.edu.co/ E-MAIL: revistainveniendi@usantotomas.edu.co

En las sentencias de tutela no hay discrecionalidad alta para la selección de la ratio decidendi pues todas las similitudes y diferencias entre conceptos y derechos pueden ser reconducidas finalmente a los parámetros mencionados.

\section{XI.}

¿Cómo justificar la selección de los argumentos fácticos y conceptuales enunciados cuando muchas veces no son expresamente señalados por los jueces? La presencia de un argumento en una sentencia independientemente de su ubicación textual en la parte motiva, que de todos modos debe ser citada, puede ser descrita mediante dos indicadores:

a. La mención del argumento (referencia explicita).

b. El desarrollo del mismo (referencia implícita).

De estas dos parejas surgen las siguientes alternativas frente a un tipo de argumento:

a.1. Es mencionado y desarrollado.

a.2. Es mencionado pero no desarrollado.

a.3. No es mencionado pero es desarrollado.

a.4. No es mencionado ni desarrollado. 


\section{REVISTA VIRTUAL VIA INVENIENDI ET IUDICANDI}

"CAMINO DEL HALLAZGO Y DEL JUICIO"

http://viei.usta.edu.co/ E-MAIL: revistainveniendi@usantotomas.edu.co

A partir de estas parejas puede rastrearse fácilmente un argumento en una sentencia particular. Cuando estamos en presencia de a.1. ya ubicados sobre un parámetro determinado, existe precedente fuertemente sobre el punto -es mentira y más una excusa que los jueces "reconstruyan la ratio"- y el juez deberá optar por manipular el precedente -aquí se podría entender esta reconstrucción de otro modo: como creación de nuevos problemas jurídicos- o apartarse expresamente de él. Los casos a.2 y a.4. son de ausencia de precedente: no se ha fallado sobre el parámetro en mención. El caso a.3. es un caso de precedente flexible: el juez posterior podría explicar el principio de la decisión de un mejor modo u organizarlo de forma distinta dentro de la argumentación del nuevo caso.

\section{XII.}

Ilustraré con un ejemplo la forma de construcción de la ratio de un caso de acuerdo a los parámetros mencionados ${ }^{47}$ :

\section{Ratio decidendi sentencia T-017-05 ${ }^{48}$}

\footnotetext{
${ }^{47}$ Omitimos las citas paginadas de la sentencia para cada afirmación por motivos de extensión. Una síntesis de jurisprudencia (un extracto) no puede omitirlas. Este cuadro, una simplificación excesiva, no se debe interpretar como un formulario listo para ser llenado. Cada jurisprudencia, cada caso, aporta elementos distintos y se puede modificar la forma de presentación de la síntesis con la finalidad de ser fieles al pensamiento de la sentencia. La síntesis de esta jurisprudencia completa puede ser enviada por correo electrónico si lo desea: jurreab2008@hotmail.com.
} 


\section{REVISTA VIRTUAL VIA INVENIENDI ET IUDICANDI \\ "CAMINO DEL HALLAZGO Y DEL JUICIO"}

http://viei.usta.edu.co/ E-MAIL: revistainveniendi@usantotomas.edu.co

\begin{tabular}{|l|l|}
\hline $\begin{array}{l}\text { Hechos para la } \\
\text { Corte }\end{array}$ & $\begin{array}{l}\text { - Se pacta una cláusula de amigable composición en un } \\
\text { contrato estatal pero no el "procedimiento" mediante el } \\
\text { cual se llevara a cabo la solución de la controversia. } \\
\text { - El trámite llevado a cabo por la amigable componedora } \\
\text { en el caso concreto no tenía ningún tipo de racionalidad ni } \\
\text { orden. }\end{array}$ \\
\hline $\begin{array}{l}\text { Problema jurídico } \\
\text { ¿Se viola el debido proceso de una de la partes si el } \\
\text { amigable componedor decide sin sujeción a un } \\
\text { procedimiento? } \\
\text { Serechos violados. } \\
\text { desarrolla. }\end{array}$ & $\begin{array}{l}\text { Debido proceso. No se viola. Argumentos: La amigable } \\
\text { composición es de naturaleza contractual y no judicial; La } \\
\text { amigable composición no es administración de justicia, no } \\
\text { es un proceso y por esta razón no le son aplicables las } \\
\text { garantías del debido proceso. }\end{array}$ \\
\hline
\end{tabular}

${ }^{48}$ Sí: es la ratio de la T-017-05 o tiene la pretensión de serlo mediante la discusión en un escenario determinado (académico). Si aplicáramos la tesis "constructivista" en la presentación de López (hechos/derechos) llegaríamos a la conclusión de que este ejercicio es inútil y deberíamos esperar a que un Juez falle otro caso. 


\section{REVISTA VIRTUAL VIA INVENIENDI ET IUDICANDI}

"CAMINO DEL HALLAZGO Y DEL JUICIO"

http://viei.usta.edu.co/ E-MAIL: revistainveniendi@usantotomas.edu.co

\begin{tabular}{|c|c|}
\hline & $\begin{array}{l}\text { lgualdad y buena fe. Se violan. A pesar de que los } \\
\text { amigables componedores no están sometidos a ningún } \\
\text { tipo de proceso y por ende las garantías del debido } \\
\text { proceso no son aplicables, de todos modos tienen } \\
\text { limitaciones para solucionar las controversias que le son } \\
\text { sometidas a su conocimiento con base en los principios de } \\
\text { buena fe e igualdad constitucionales. En virtud de } \\
\text { aquellos, ellos deben señalar al inicio del tramite } \\
\text { contractual explícitamente los pasos que seguirán a fin de } \\
\text { que las partes queden en igualdad de armas. En el caso } \\
\text { concreto estas reglas no fueron explícitamente señaladas } \\
\text { ni por el Centro de Amigable Composición ni por la } \\
\text { amigable componedora y por esta razón ambas partes } \\
\text { quedaron una situación de indefensión amparable en tutela } \\
\text { en el caso de una de ellas. }\end{array}$ \\
\hline $\begin{array}{l}\text { Solución. } \\
\text { Existencia de } \\
\text { mecanismos de } \\
\text { defensa judicial }\end{array}$ & No se menciona ni se desarrolla. \\
\hline $\begin{array}{l}\text { Solución. Perjuicio } \\
\text { irremediable }\end{array}$ & No se menciona ni se desarrolla. \\
\hline Decisum & $\begin{array}{l}\text { Orden al amigable componedor para que fije el iter } \\
\text { mediante el cual resolverá la controversia. }\end{array}$ \\
\hline
\end{tabular}

En este caso podemos observar que: 


\section{REVISTA VIRTUAL VIA INVENIENDI ET IUDICANDI}

"CAMINO DEL HALLAZGO Y DEL JUICIO"

http://viei.usta.edu.co/ E-MAIL: revistainveniendi@usantotomas.edu.co

a. No hay pronunciamiento sobre el parámetro "existencia de mecanismos de defensa". Esto quiere decir que no hay pronunciamiento sobre el punto y un juez de inferior jerarquía inclusive partiendo de la misma interpretación iusfundamental podría negar la tutela estatal.

b. Tampoco hay precedente sobre el parámetro "perjuicio irremediable". Un juez, podría apartarse o distinguir el caso de la interpretación iusfundamental diciendo, por ejemplo, que no se configura un perjuicio irremediable que amerite la tutela aunque se contare con una acción judicial pertinente.

c. La interpretación iusfundamental del derecho a la buena fe y la igualdad constituyen precedente y requieren de apartamiento explicito. En el caso de los jueces de inferior jerarquía la carga es más exigente.

En esta sentencia la Corte considera "indispensable" que los Centros de Amigable Composición desarrollen el iter contractual en tres etapas: apertura, investigación y decisión. Desde la perspectiva constructiva del precedente podría discutirse si, por ejemplo, esta exigencia es un dictum -ratio constructivista- o hace parte de la ratio -ratio formalista-. Un Juez podría considerar, por ejemplo, dictum a los tres criterios y no compararlos con los hechos del caso sometido a su consideración. Su examen se limitaría a observar si se fijo o no explícitamente el trámite contractual aunque no fuese el mismo enunciado por la Corte. 


\section{REVISTA VIRTUAL VIA INVENIENDI ET IUDICANDI}

"CAMINO DEL HALLAZGO Y DEL JUICIO"

http://viei.usta.edu.co/ E-MAIL: revistainveniendi@usantotomas.edu.co

\section{Conclusiones}

Primera: La división realizada por Diego López entre una ratio formalista y antiformalista fundamentada en la división entre "hechos" y "conceptos" -0 "derechos"- es una forma inadecuada de descripción de la ratio decidendi porque vincula débilmente a los jueces al precedente. Los hechos no están al lado de la ratio antiformalista y los conceptos de una formalista.

Segunda: No existe un concepto unitario de ratio decidendi. A cada tipo de sentencia judicial corresponden tipos distintos de hechos relevantes y, por tanto, distintos tipos de ratio decidendi.

Tercera: Solo puede hablarse de similitud fáctica estrecha si el tipo de sentencia citada como precedente es equivalente a la posterior. Entre sentencias de distinto tipo debería analizarse primero el valor y fuerza de los precedentes -análisis dinámico de la jurisprudencia-.

Cuarta: Una ratio constructivista justifica mejor una vinculación fuerte al precedente que una ratio voluntarista -cláusula Angarita- pero únicamente a condición de ofrecer criterios de selección de argumentos a los cuales pueda reconducirse la discusión entre muchas personas. Los jueces posteriores encuentran el verdadero sentido de las decisiones anteriores en la medida en que 


\section{REVISTA VIRTUAL VIA INVENIENDI ET IUDICANDI}

"CAMINO DEL HALLAZGO Y DEL JUICIO"

http://viei.usta.edu.co/ E-MAIL: revistainveniendi@usantotomas.edu.co

dialogan sobre una ratio que se puede conocer, leer y discutir. Una ratio que nunca se sabe cual es so pretexto de esta construcción permanente de la jurisprudencia es una forma de vinculación débil de los jueces al precedente y una apertura a la arbitrariedad judicial.

Quinta: Son los jueces y abogados quienes en los debates diarios discuten y construyen los criterios que pueden ser considerado ratio decidendi de un caso. De jueces y abogados se espera no sólo que citen la jurisprudencia sino la justifiquen. Sin embargo, si estos criterios no son reconducibles a debates más o menos uniformes no hay disciplina del precedente.

Sexta: Los extractos de jurisprudencia son absolutamente normales para citar tanto hechos y conceptos por lo que no podrían ser censurados como manifestación de un "conceptualismo dominante". Estos extractos y comentarios de la jurisprudencia ayudan a la reconstrucción del material previo siempre y cuando correspondan a un método, sino infalible, por lo menos regular de lectura.

\section{Referencias}

Batiza Rodolfo (1992). "La "ratio decidendi" en la jurisprudencia y doctrina angloamericanas" En: Juridica. Anuario del Departamento de Derecho de la Universidad Iberoamericana.

Nro.

21. 


\section{REVISTA VIRTUAL VIA INVENIENDI ET IUDICANDI}

"CAMINO DEL HALLAZGO Y DEL JUICIO"

http://viei.usta.edu.co/ E-MAIL: revistainveniendi@usantotomas.edu.co

http://www.juridicas.unam.mx/publica/librev/rev/jurid/cont/21/pr/pr7.pdf Consultado el 12 de agosto de 2009.

Gordillo, Roberto \& López Medina, Diego Eduardo (2002). "Consideraciones ulteriores sobre el análisis estático de la jurisprudencia”. Revista de Derecho Público. Facultad de Derecho Universidad de los Andes. Bogotá: V. 27, n. 101, p 3-47.

López Medina, Diego Eduardo (2002). "El derecho de los jueces". Ediciones Uniandes, Facultad de Derecho. Serie Lex Nova. Cuarta reimpresión. Primera edición, 2002. Bogotá, 2002.

Olano García, Hernán Alejandro (2004). "Tipología de nuestras sentencias constitucionales". Vnuversitas, número 108, Diciembre de 2004, p.p. 571-602. En: http://www.javeriana.edu.co/Facultades/C_Juridicas/pub_rev/documents/13Olanou It..pdf Recuperado el 23 de junio de 2009

Republica de Colombia. Corte Constitucional. Sentencia de constitucionalidad C836 de 2001. Magistrado Ponente: Rodrigo Escobar Gil. En. http://190.24.134.68/relatoria/2001/C-836-01.rtf. Recuperado 16 de julio de 2009 


\section{REVISTA VIRTUAL VIA INVENIENDI ET IUDICANDI}

"CAMINO DEL HALLAZGO Y DEL JUICIO"

http://viei.usta.edu.co/ E-MAIL: revistainveniendi@usantotomas.edu.co

Republica de Colombia. Corte Constitucional. Sentencia de revisión de tutela SU047 de 1999. Magistrados Ponentes: Carlos Gaviria Díaz y Alejandro Martínez Caballero. http://190.24.134.68/relatoria/1999/SU047-99.rtf. Recuperado 13 de julio de 2009.

República de Colombia. Corte Constitucional. Sentencia de revisión de tutela T249 de 1998. Magistrado Ponente: Hernando Herrera Vergara Vergara. Caballero. http://www.dmsjuridica.com/CODIGOS/LEGISLACION/Sentencias/T-249-98.rtf. Recuperado 9 de octubre 2009.

Villamil Portilla, Edgardo (2004), Estructura y redacción de la sentencia judicial. En:

http://portal.oit.or.cr/dmdocuments/justicia_laboral/09.\%20estructura\%20de\%20la \%20sentencia.pdf. Recuperado 23 de junio de 2009.

Vernengo, R. J. (1977). La interpretación de los hechos. En: "La interpretación jurídica". Universidad Nacional Autónoma de México. En: http://www.bibliojuridica.org/libros/2/846/4.pdf. Recuperado 23 de junio de 2009. 